\title{
GEOHISTÓRIA DO PLANEJAMENTO NACIONAL BRASILEIRO: NARRATIVAS E REFLEXÕES
}

\author{
Yuri Victor Melo ${ }^{1}$
}

\begin{abstract}
Resumo: Investiga-se aqui a geohistória do planejamento estatal brasileiro, pormenorizando suas diferentes concepções teórico-práticas, tendências e reverberações socioespaciais que orientaram os processos e planificações executivos governamentais. A pesquisa estruturou-se a partir da revisão bibliográfica temática de artigos, sites, teses e livros correlatos, comparando-se espaço-temporalmente linhas narrativas e tendências geohistóricas, alicerçadas na cronologia da política pública federal, especialmente a nível nacional. Evidenciou-se a ausência de uma concepção padrão que oriente a elaboração das várias planificações nacionais, patenteando a inexistência de sólidos projetos de Estado no Brasil. Diversas propostas de planejamento brasileiro se mostraram pouco eficazes, desiguais e custosas, além de consideradas em processo recente e dialético de maturação. Esperase ter evidenciado a importância do caráter sociopolítico e territorial para a feitoria de pósteros planos nacionais mais justos e democráticos.
\end{abstract}

Palavras-chave: planejamento; geohistória; desenvolvimento.

\section{GEOHISTORY OF BRAZILIAN NATIONAL PLANNING: NARRATIVES AND REFLECTIONS}

\begin{abstract}
The geohistory of Brazilian state planning is investigated here, detailing its different theoretical-practical conceptions, trends and socio-spatial reverberations that guided government executive processes and planning. The research was structured based on the thematic bibliographic review of articles, websites, theses and related books, comparing spatio-temporal narrative lines and geohistorical trends, based on the chronology of federal public policy, especially at the national level. It was evident the absence of a standard conception that guides the elaboration of the various national plans, showing the absence of solid-State projects in Brazil. Several Brazilian planning proposals proved to be ineffective, uneven and costly, in addition to being considered in a recent and dialectical process of maturation. It is hoped to have evidenced the importance of the socio-political and territorial character for the making of more just and democratic national planning.
\end{abstract}

Keywords: planning; geohistory; development.

\section{GEOHISTORIA DE LA PLANIFICACIÓN NACIONAL BRASILEÑA: NARRATIVAS Y REFLEXIONES}

Resumen: Aquí se investiga la geohistoria de la planificación estatal brasileña, detallando sus diferentes concepciones teórico-prácticas, tendencias y reverberaciones socioespaciales que guiaron los procesos ejecutivos y la planificación del gobierno. La investigación se estructuró a partir de la revisión bibliográfica temática de artículos, sitios web, tesis y libros relacionados, comparando líneas narrativas espacio-temporales y tendencias geohistóricas, con base en la cronología de la política pública federal, especialmente a nivel nacional. Se evidenció la ausencia de una concepción estándar que oriente la elaboración de los distintos planes nacionales, evidenciando la ausencia de proyectos de Estado sólido en Brasil. Varias propuestas de planificación brasileñas demostraron ser ineficaces, desiguales y costosas, además de ser consideradas en un reciente y dialéctico proceso de maduración. Se espera haber evidenciado la importancia del carácter sociopolítico y territorial para la realización de planificaciones nacionales más justas y democráticas.

Palabras clave: planificación; geohistoria; desarrolloo.

\footnotetext{
1 Licenciado e bacharelando em Geografia pela Universidade Federal do Espírito Santo (UFES). Email: ymelllo@hotmail.com. Orcid: https://orcid.org/0000-0002-9008-3414
} 


\section{Introdução}

Discorrer acerca do (s) planejamento (s) sempre se mostra uma tarefa árdua, por, sinteticamente, referir-se a uma discussão de possíveis. Este debate se apresenta há tempos nas sociedades humanas das mais distintas culturas, perpassando por diversas matrizes de interpretação e envolvendo os mais distintos agentes e grupos sociais.

Segundo Amora (2009, p. 550), o termo "planejamento" diz respeito ao "1. Ato ou efeito de planejar; 2. trabalho de preparação; 3. elaboração por etapas”. Ademais, o Dicionário Michaelis (2020, online) adita que a semântica de tal verbete pode corresponder a "organização de uma tarefa com a utilização de métodos apropriados" ou ainda a "determinação de ações para atingir as metas estipuladas por uma empresa, órgão do governo etc.; planificação". Assim, torna-se evidente que o conceito de planejamento está intimamente inter-relacionado com práticas socioespaciais concretizadas para determinado fim.

No transcorrer da história, desde pelo menos o século XVI, já se encontram registros da busca pela materialização do ideal de planejamento nas emergentes cidades e vilas, tanto europeias quanto latino-americanas. Este plano urbano ganhará ainda mais valor, para burgueses e Estados Nacionais, a partir do século XVII, com a maior difusão dos valores iluministas e o posterior desenvolvimento industrial. Nas palavras de Raquel Rolnik (1988, p. 58):

A lógica da racionalidade, do cálculo e da previsão, que emerge a partir das práticas econômicas do grande comércio e da manufatura, penetra assim na produção do espaço, com planos e projetos debaixo do braço.

No século XIX, o ideário de racionalidade, sustentáculo dos mais distintos planejamentos, chega ao seu ápice, instrumentalizando-se a partir de constituição de ciências parcelares. Deste modo, como nos lembra Carlos Walter Porto Gonçalves (2005, p. 34), “a natureza, cada vez mais um objeto a ser possuído e dominado, é agora subdividida em física, química, biologia. O homem em economia, sociologia, antropologia, história, psicologia etc.”. Nesse bojo produtivo, consubstanciam-se, epistemologicamente e institucionalmente, as ditas ciências sociais.

Torna-se evidente, então, que desde os primórdios, as "ciências do homem" estavam posicionadas intimamente sob a alçada do "triunfo desse mundo pragmático" (GONÇALVES, 2005, p. 34), regido, neste momento, predominantemente através dos mandos dos impérios europeus. Logo, ciências emergentes, a exemplo da Geografia, a qual, desde a sua mais tenra sistematização, almejava "entrosar o conhecimento da natureza e o conhecimento da sociedade 
para dentro de si mesma" (SOUZA, 2018, p. 277); foram cooptadas como meio técnicocientífico que justificasse, auxiliasse e amparasse as ações das potências europeias.

Melhor exemplificando o caso da ciência geográfica, percebe-se que a Geografia, com "G" maiúsculo, sempre apresentou inter-relações com o planejamento, principalmente estatal, seja de crítica as suas tomadas de decisão, seja de legitimação a suas atitudes. A própria gênese dessa ciência, no início do século XIX, deu-se como resposta a uma busca por melhor organização dos principados e reinos que comporiam a futura nação alemã (MORAES, 2007).

Feita tal contextualização história, urge, pois destacar a relevância desse tema, já que "pensar a respeito do espaço depende de quem o pensa" (CORRÊA, 1993, p. 25). Refletir sobre o espaço e o planejamento estatal apresenta-se, mais do que nunca, como tarefa fundamental por parte das ciências humanas e sociais. O caso brasileiro dispensa maiores comentários acerca de sua sobeja relevância.

Deste modo, esta investigação discute e reflete sobre diversos entendimentos possíveis acerca da práxis do planejamento estatal brasileiro, destacando suas respectivas aplicações e reverberações socioespaciais. Para tal, contextuando-se o desenvolvimento dos percursos sociopolíticos do planejamento nacional.

Metodologicamente, destacam-se narrativas, processos e elementos espaço-temporais que auxiliam e corroboram as presentes elaborações. Ademais, se evidenciam as relações socioeconômicas que perpassam diacronicamente o Estado brasileiro, as quais oferecem suporte para a identificação de tendências sociopolíticas e para a concepção de investigações outras. Logo, engendra-se uma pesquisa a partir de revisão e comparação crítica de eventos e fenômenos, alicerçada em investigação bibliográfica e sob a metodologia analítica geohistórica.

Somente a partir de uma compreensão crítica das práticas têmporo-espaciais se poderá (re)pensar geohistoricamente outros planejamentos possíveis, os quais contribuam para desvelar as mazelas e percalços que as políticas de Estado impõem a sociedade, além de objetivar uma estrutura organizacional mais integradora, eficiente e inclusiva. Desse modo, tem-se em mente que "o processo de planejamento é necessariamente conflituoso, contingente, tenso e em processo" (BRANDÃO, 2014, p. 215).

\section{Metodologia}

A presente investigação utiliza-se do aporte metodológico geohistórico para embasar-se analiticamente tocante as narrativas e eventos concernentes ao planejamento nacional brasileiro, discorrendo acerca de suas trajetórias tendenciais e de suas cronologias sociopolíticas. Os termos de Carneiro (2018, p. 35) bem sintetizam o fazer epistemológico geohistórico aqui anelado: 
O pesquisador em geografia histórica deve se preocupar com o estudo das mudanças no espaço e no tempo; buscar em eventos e épocas pretéritas as variáveis geográficas e os aspectos territoriais chaves para compreensão dos contextos passado e presente, que possuem influência decisiva nos processos e acontecimentos históricos e que irão explicar a configuração e a organização do espaço em foco.

Neste ensejo, destaca-se a ampla revisão bibliográfica temática de artigos, sites, teses e livros correlatos. Tal procedimento é basilar para a estruturação analítica de reflexões e para a explicitação de tendências políticas diacrônicas do planejamento estatal brasileiro. Retoma-se, assim, considerações outras, propostas por pesquisadores de diferentes áreas do saber, tocantes a compreensão das narrativas espaço-temporais da planificação nacional, a exemplo dos estudos de Ianni (1971) e Pinho (2016).

\section{Percursos e Tendências Inaugurais da Geohistória do Planejamento Nacional}

Historicamente, pode-se reatar que as narrativas e discussões do Estado brasileiro acerca do planejamento remontam desde, pelo menos, o final do século XIX. Nesse período, sobretudo após a Proclamação da República (1889), algumas propostas de planejamento vieram à tona, a fim de melhor estabelecer as diretrizes político-econômicas que orientariam os rumos do Estado nacional (SOUZA, 2004).

Este, então, novo contexto histórico-social (pós 1889) apresentou-se como marco transicional para outro momento político-espacial no país. Como elemento marcante desta política vindoura, há a substituição de várias décadas de governo monárquico para um ambiente republicano, mesmo que de caráter oligárquico durante alguns decênios (SOUZA, 2004).

Esta nova etapa do desenvolvimento da nação deveria vir acompanhada de novos ideais e, assim, o planejamento se mostrou um bom modo de tentar colocar estes projetos em prática. Nos últimos anos do século XIX, foram propostos alguns planos para reafirmar a ordem desse novo regime de governança, a exemplo do Plano de Viação e do Plano de Recuperação Econômico-Financeira (SOUZA, 2004).

Apesar das incipientes planificações de caráter socioeconômico, será somente a partir dos anos de 1930, durante o Governo Vargas, que o Brasil entrará de vez na elaboração política de seguidos planejamentos estatais. Nesta década, com a maior difusão dos meios de comunicação, a exemplo do rádio, e o caráter nacionalista do governo, serão propostos planejamentos que carregam em si mesmos elementos que transcenderão e reaparecerão em inúmeros planos futuros de outros governantes. 
Dentre as concepções, práticas e ideais comuns que justificam vários planejamentos estatais nacionais, podem-se destacar três aspectos: 1) o nacionalismo/populismo de alguns governos, 2) a construção de obras faraônicas e 3) a busca por uma maior integração regional (IANNI, 1971).

No transcorrer de alguns governos, a exemplo da chamada "Era Vargas", certos governantes assumiram posturas populistas que os justificavam enquanto defensores da nação e dos valores mais representativos do ideário de nacionalidade brasileira. Assim, comumente, estes mandatários constituíam suas reputações utilizando-se da propagação de uma ideologia desenvolvimentista, pautada, em diversos casos, numa maior interferência estatal nos assuntos econômicos, além de expressa em seus modelos de planejamento de governo (JUSTEN; FROTA, 2017), (MEMORIAL DA DEMOCRACIA, 2019).

Outrossim, diversos chefes de Estado também usufruíam da proposição e construção de obras monumentais para a divulgação de seus ideários, a exemplo dos governantes do período da ditadura civil-militar. Para a efetivação das planificações, os governos se pautavam no simbolismo da força, do poder, do desenvolvimento pungente e da valorização da nacionalidade (MEMORIAL DA DEMOCRACIA, 2019). Apesar disto, como nos alerta Robert Kurz (2001, não paginado):

A maioria dos projetos monumentais é absurda, muitos são interrompidos, todos são deficitários. Os efeitos sobre a paisagem e a natureza costumam ser avassaladores, pois o planejamento, autocrático, ignora as considerações ecológicas. Sempre foram, até hoje, os potentados dos países mais miseráveis que quiseram se eternizar para a posteridade com uma espécie de mania faraônica.

Ademais, como tendência frequentemente presente nos documentos dos planejamentos estatais pós governo Vargas, há uma busca, por parte de vários presidentes e coligações políticas, por maior integração regional. Tais planificações se baseariam em regionalizações com fins desenvolvimentistas, as quais podem ser exemplificadas a partir dos casos da Superintendência do Desenvolvimento do Nordeste (Sudene), da Superintendência do Desenvolvimento da Amazônia (Sudam) e do projeto RADAMBRASIL. Mesmo que sob diferentes enfoques, estes planejamentos estatais incorporavam e usufruíam, em linhas gerais, do sentido políticoetimológico do conceito de região.

A semântica original da acepção supracitada referencia-se no caráter político da conceituação. Portanto, vale destacar que "região vem de regere, isto é, dominar, reger" (LACOSTE, 2012, p. 63) e esta é uma das principais funções do discurso de integração regional. 
Francisco de Oliveira (1977, p. 29) ainda nos lembra acerca das relações capitalistas envolvidas pelo termo em debate:

Uma "região"; seria, em suma, o espaço onde se imbricam dialeticamente uma forma especial de reprodução do capital, e por consequência uma forma especial da luta de classes, onde o econômico e o político se fusionam e assumem uma forma especial de aparecer no produto social e nos pressupostos da reposição.

Dito isso, vale mencionar que, para além das considerações, principalmente atinentes a Superintendência do Desenvolvimento do Nordeste (Sudene), o autor referenciado sintetiza a(s) posicionalidade(s) funcionalistas das políticas de planejamento estatais.

Tornando à baila o atual estágio do sistema capitalista nacional, urge-se destacar as compreensões de Oliveira (1977, p. 29 e 30) acerca da dialeticidade histórico-social de tais planificações técnicas teórico-práticas:

O planejamento não é, portanto, a presença de um Estado mediador mas, ao contrário, a presença de um Estado capturado ou não pelas formas mais adiantadas da reprodução do capital para forçar a passagem no rumo de uma homogeneização, ou conforme é comumente descrito pela literatura sobre planejamento regional, no rumo da "integração nacional"; Nem ainda o planejamento é uma forma "neutra" dessa presença; ao contrário, ele é no mais das vezes uma forma transformada da própria luta de classes, tanto ao nível das contradições na reprodução global do capital quanto ao nível das contradições entre as formas diferenciadas, "regionais"; daquela reprodução e as mesmas formas das relações de produção.

De maneira sistematizada, certos autores, a exemplo de Octávio Ianni (1971), defendem que, sob perspectiva geohistórica, diversos governantes brasileiros apresentam padronizações em seus percursos, discursos e planejamentos políticos durante seus respectivos mandatos. Desta forma, a análise da historiografia nacional possibilita ressaltar, em linhas gerais, que os mais diversos planos político-econômicos e seus contextos correlatos, a despeito de suas especificidades, alternaram-se em torno de dois polos.

Estes pontos interpretativos podem ser basicamente resumidos em, por um lado, uma tendência à defesa de políticas nacionalistas, almejando o desenvolvimento de um capitalismo nacional; por outro, a busca por um modelo desenvolvimentista de forte filiação ao sistema capitalista internacional. Evidencia-se, portanto, uma ciclicidade histórica tocante às compreensões do que seja o desenvolvimento e, nessa toada, também se questiona o ato de planejar (IANNI, 1971).

De modo geral, o referido momento histórico de ascensão dos modelos de planejamento do Brasil, tendo como marco a "Era Vargas", diz respeito a uma compreensão nacionaldesenvolvimentista da gestão governamental. Na década de 1930, o governo varguista anelava 
responder as transições contextuais e os tensionamentos históricos perpassados pela nação (JUSTEN; FROTA, 2017).

No início dos anos de 1930, a conjuntura brasileira retratava internamente a manutenção do poder político-econômico nas mãos de uma oligarquia agrária ao passo que, internacionalmente, ocorria a Crise da Bolsa de Nova York (1929) e suas consequentes reverberações geoeconômicas. Estes elementos geohistóricos propiciaram uma "krísis" na política brasileira, a qual possibilitou a Getúlio Vargas o anseio a uma "nova concepção de Estado como fomentador do desenvolvimento nacional" (JUSTEN; FROTA, 2017, p. 6 e 7).

A partir do intitulado "Governo Constitucional”, o qual perdurou de 1934 a 1937, Vargas passará a elaborar diversos modelos de planejamento com fins ao desenvolvimento do país. O governante instaurará numerosos órgãos, autarquias, instituições e comissões, todos subordinados ao governo central; para a execução mais eficaz destes planos. Dentre estes órgãos destaca-se o Conselho Federal de Comércio Exterior, considerado por Rezende (2011, p. 177) “como o primeiro organismo governamental com funções típicas de um órgão de planejamento". Ademais, Souza (2004, p. 102) ressalta que "as iniciativas que vigoraram nessas duas décadas de 30-40 culminaram com uma forte intervenção do Estado na sociedade, através do planejamento governamental".

Dentre as instituições idealizadas pelo governo federal, uma merece destaque por sua pretensa função de contribuir tecnicamente para a consolidação do sistema de planejamento territorial da nação, o Instituto Brasileiro de Geografia e Estatística (IBGE). Esta agência, proposta em 1934, irá de fato alavancar os estudos regionais brasileiros em suas mais diversas facetas, principalmente após sua instalação por completa em 1938 (ALMEIDA, 2004).

Em consonância com a criação do IBGE, foram propostos outros relevantes órgãos organizacionais, a exemplo do Conselho Federal de Comércio Exterior, um dos primeiros órgãos de planejamento nacional. Como base teórica que fundamentaria todas essas propostas, urgiu-se a necessidade de investir em estudos técnico-científicos que auxiliassem e amparassem esses planos (IANNI, 1971). Neste contexto, o papel da ciência geográfica merece destaque.

No ano de 1934, surge, então, o primeiro curso de Geografia no Brasil, sediado na Universidade de São Paulo (USP) e organizado de acordo com as propostas e diretrizes da denominada "missão francesa". Este curso deveria, no nível acadêmico, buscar responder aos anseios por um maior conhecimento da nação, com fins ao planejamento de governo, liderado pelo IBGE. No ano seguinte, em 1935, é instalado o segundo curso de Geografia no país, na então Universidade do Distrito Federal (UDF), atual Universidade Federal do Rio de Janeiro (UFRJ), estruturado sob os mesmos moldes francófonos (ALMEIDA, 2004). 
Estas graduações foram fundamentais para consolidação do papel do geógrafo no contexto nacional, pois foram coordenadas, principalmente, por dois eminentes geógrafos franceses, Pierre Monbeig e Pierre Deffontaines. Ambos os cientistas estavam em profundo contato com órgãos governamentais, a exemplo do IBGE, e, dessa forma, se apresentavam como bastiões de uma Geografia que ainda estava por se afirmar. Pierre Deffontaines ainda foi um dos fundadores da Associação dos Geógrafos Brasileiros (AGB), importante instituição para a Geografia brasileira (ALMEIDA, 2004).

A partir de 1937, o Governo Vargas adotaria medidas de caráter ditatorial, a fim de garantir sua manutenção no poder. Tal período perdurou até 1945 e fícou conhecido como "Estado Novo". Durante este contexto, Vargas lançou mão de diversos planos, tanto para se justificar no poder quanto para buscar um desenvolvimento admitido como genuinamente nacional. Nas palavras de Souza (2004, p. 103):

É a partir de um discurso nacionalista, estatizante e intervencionista, principalmente, que o Estado brasileiro fomenta iniciativas como a valorização do capital e da empresa nacional, dentre outros, para viabilizar a política de industrialização, tendo como base algumas ações que até aquele momento não se constituíam, ainda, em um planejamento governamental. Tais iniciativas tinham como objetivos construir um Estado capitalista brasileiro que fosse dotado de uma economia forte, com base nacional, e, desta forma, viabilizar as suas relações de produção com maior ênfase na presença do setor estatal no processo de industrialização.

Neste hiato de ditadura varguista, Getúlio Vargas lança mão, por exemplo, do "Plano Cohen", documento que difundia uma suposta iminência de ataque comunista a ordem do país. Como resposta a ameaça, Vargas pôde legitimar seu regime ditatorial a partir do fechamento do Congresso Nacional e da proposição de uma nova Constituição (MEMORIAL DA DEMOCRACIA, 2019).

No âmbito econômico, parte das ações getulistas empreendidas durante o "Estado Novo" estavam alinhadas aos moldes do chamado Plano Especial. Este planejamento visava melhor distribuição dos recursos da nação, com fins à maior acurácia no investimento setorizado das finanças. As áreas focais do desenvolvimento brasileiro, de acordo com este plano, deveriam responder pela maciça instalação de indústrias de base, pela implementação de equipamentos públicos e pela defesa à soberania nacional (JUSTEN; FROTA, 2017).

Portanto, a partir das considerações supracitadas, percebe-se que a materialização do ideal racionalista planificador ocorreu, efetivamente, de maneira tardia no Brasil. $\mathrm{O}$ engendramento consolidado das primeiras propostas e discussões acerca do planejamento estatal emergiu somente a partir do período historiográfico republicano nacional e multiplicou-se aos montes a datar do Governo Vargas. 
Deste modo, percebe-se que esta geohistória tardia da planificação territorial à brasileira resultou em numerosos planejamentos pouco eficazes, descontínuos e efêmeros, dos mais diferentes governos. A instabilidade político-social nacional consubstanciou-se de modo patente na diversidade de ideais propostos por planificações sequenciais.

A Primeira República Brasileira evidenciou, então, planejamentos de caráter fortemente militarista e/ou oligárquico, os quais concediam benesses aos setores hegemônicos da política brasileira e apresentavam tensões entre si. Outrossim, este período marcou-se pelo nacionalismo varguista, difusão dos ideários populistas, maior disseminação dos meios de comunicação, criação das primeiras autarquias e órgãos planificadores e pela ditadura do "Estado Novo".

Assim, teceram-se as bases para os futuros planejamentos nacionais, os quais, como nos lembra Ianni (1971), irão pendular entre posturas nacionalistas e internacionalistas. Tais planos de governo almejarão sustentar-se enquanto projetos mais consolidados, diversamente planificados e maduros, entretanto se utilizarão de já conhecidos artifícios e mecanismos político-econômicos e, em diversos casos, não se comprometerão com as liberdades individuais e com a justiça socioespacial.

Nestas contexturas, destacam-se as considerações de Pinho (2016), o qual ressalta o primeiro governo varguista como marco inaugural do Nacional-desenvolvimentismo no país. Tal aporte macroeconômico estruturará as bases para a modernização capitalista brasileira, até meados da década de 1980, ao consubstanciar-se em diversos planejamentos governamentais vindouros.

\section{As diversas planificações brasileiras a novas respostas conjunturais}

Nos idos de 1940, Eurico Gaspar Dutra assume a presidência do país, após 15 anos de mandato de Getúlio Vargas. Dutra, apoiado por outros agentes e grupos socioeconômicos e fundamentado por distintos valores ideológicos de seu predecessor, buscará a realização de um planejamento de governo bastante díspar se comparado a governança varguista.

De 1946 a 1951, Gaspar Dutra implementou uma política econômica de caráter liberal internacionalista. Para isso, refreou o anseio ao desenvolvimento exclusivista da indústria nacional e ampliou fortemente as taxas de importação. Ao final de seu mandato, o presidente se viu obrigado a buscar maior controle sobre as importações e maior regulamentação das mesmas, sob o pretex to de queda nas reservas cambiais (IANNI, 1971).

Em 1950, é aprovada no Congresso Nacional a principal planificação do governo Dutra, o denominado "Plano SALTE". Este planejamento visava alavancar o desenvolvimento nacional a 
partir de amplos investimentos nos setores de saúde, alimentação, transporte e energia. Devido a incompatibilidade financeira e as ineficiências técnicas, este plano de governo foi apenas parcelarmente executado ao final do mandato de Eurico Gaspar Dutra (SARETTA, 1995) (FUNDAÇÃO GETÚLIO VARGAS, 2019).

No início da década de 1950, a fragilidade da experiência desenvolvimentista do governo Dutra, alinhada a uma nova conjuntura geohistórica, possibilitou a Getúlio Vargas que reatasse ao poder, desta vez democraticamente eleito. As matrizes ideológicas do novo mandato varguista foram semelhantes às dos primeiros quinze anos do mandatário na presidência da república, com destaque para a busca desenfreada pelo desenvolvimento nacional e a propagação de um nacionalismo profundamente associado à imagem paternalista e populista de Vargas.

De 1951 a 1954, Getúlio Vargas se debruçará insistentemente sobre a questão do desenvolvimento econômico no Brasil. Neste período, proporá instituições e empresas públicas que irão definir os moldes do crescimento econômico nacional, além de reafirmar o próprio governo. Dentre estas instaurações getulistas, serão propostas a criação da Petrobrás, da Eletrobrás e do Banco Nacional de Desenvolvimento Econômico (BNDES) (SOUZA, 2004).

Após período de instabilidade política que marca o ínterim da sucessão de Vargas, assume a presidência nacional, de 1956 a 1961, Juscelino Kubitschek. Este presidente apresentase como visionário do desenvolvimento da nação e defensor de um modelo de governança desenvolvimentista, a partir de ações, posicionamentos e decisões político-econômicas alinhadas, em diversos contextos, ao capitalismo estadunidense (MEMORIAL DA DEMOCRACIA, 2019).

Durante seu mandato, Juscelino proporá o denominado "Plano de Metas", sob o lema do desenvolvimento de "50 anos em 5". Os dizeres de Kon (1994, p. 50) bem resumem os pressupostos geoeconômicos que possibilitaram a busca pela efetivação desta planificação: "a articulação entre o capital privado e o nacional, e entre o capital estrangeiro e o Estado, visualizada no plano, desempenhou papel importante no processo de industrialização que se acelerou acentuadamente no período".

Sob a alçada do "Plano de Metas" estavam, principalmente, o desenvolvimento dos setores de indústrias de base e energético, com a construção de duas hidrelétricas (Três Marias e Furnas), e de transportes, principalmente de matriz rodoviarista. Juscelino inaugurou mais de 20mil quilômetros de rodovias durante o seu mandato. Além disso, como um dos principais objetivos de seu governo, o presidente efetivou a construção da nova capital federal, a cidade de Brasília (KON, 1994), (MEMORIAL DA DEMOCRACIA, 2019).

Das propostas de planejamento à brasileira vivenciadas até então, "a primeira experiência que considerava o processo global e contínuo de planejamento, e que foi efetivamente aplicada 
no país, data de 1956, com o Plano de Metas" (KON, 1994, p. 50). Desta forma, valem as palavras de Horieste Gomes (1984, p. 120) para a melhor compreensão acerca das dificuldades e da importância socioespacial de se refletir sobre o planejar:

A realização de planos em diferentes níveis de organização, submetidos a objetivos bem definidos em termos de aplicabilidade e rentabilidade, são necessidades imperiosas decorrentes da realidade objetiva que se encontra no mundo da natureza, da sociedade e do indivíduo. Desde a escala do local à nacional, o planejamento deverá ser uma constante em vista da sociedade estar submetida a dinâmica dialética do movimento e regida por leis históricas.

Posteriormente ao mandato de Juscelino Kubitschek, o curto governo de Jânio Quadros que o sucede é marcado por uma frágil base política e uma ausência de plano de governo elucidativo. Desta forma, o então mandatário não propôs nenhum modelo sólido de planejamento socioeconômico (SOUZA, 2004).

Entre 1961 e 1963, antecedendo o período do regime civil-militar brasileiro, o governo João Goulart, sucessor de Jânio à presidência, propõe o "Plano Trienal". Este plano almejava uma reestruturação econômica do país, com vistas à diminuição gradativa das taxas inflacionárias, a maior integração regional e um desenvolvimento social mais justo e igualitário (JUSTEN; FROTA, 2017), (SOUZA, 2004).

A planificação do mandato de Goulart não se demonstra satisfatória para a resolução dos problemas socioeconômicos da nação e não angaria grande apoio nos setores sociais e nas bases governistas. Deste modo, setores oposicionistas, a exemplo dos militares e de certas parcelas da sociedade civil, aproveitam-se das fragilidades conjunturais para associar-se a certos grupos e agentes sociais e instaurar o Golpe Civil-Militar, em 1964 (JUSTEN; FROTA, 2017) (SOUZA, 2004).

Nota-se assim, embasando-se nas considerações em debate, que o ínterim entre a primeira governança varguista e o Golpe Civil-Militar de 1964, marcou-se pela difusão desenfreada de diversas planificações díspares entre si e pelo investimento nos setores industriais e de engenharia urbana.

A partir dos anos de 1950, percebeu-se a maior inserção dos meios técnico-científicos e dos ideários de integração regional na concepção das planificações nacionais. Deste modo, alavancou-se a produção e a valorização do espaço construído, além da apropriação de novas extensões territoriais, a exemplo da maciça construção de rodovias e da estruturação da cidade de Brasília.

Todavia, a exemplo do que viria a acontecer principalmente durante os governos do regime militar, foram relegados os "custos externalizados" (LEONARD, 2011, p. 27) de tais 
planificações e marginalizados certos setores e agentes sociais. Portanto, diversos planejamentos do período em discussão não se efetivaram em suas totalidades por, dentre outras razões, ambicionarem plano-discursos e ideologias inexequíveis socioeconomicamente, a partir da constituição de obras extremamente custosas à sociedade.

\section{Planejamento faraônico, discursos unificadores e ressalto ao poder - Os planejamentos do Regime Militar}

De 1964 a 1985, a política nacional foi governada por diversos presidentes componentes do regime militar brasileiro. A despeito de suas orientações ideológicas, certos elementos se mostraram centrais e unificadores para execução dos planejamentos socioeconômicos dos diferentes governos militares (MEMORIAL DA DEMOCRACIA, 2019).

A ditatura militar preconizou, durante mais de dois decênios, a busca pela integração nacional, um modelo nacional-desenvolvimentista a todo vapor, com a construção de obras dantescas; uma valorização demasiada pelo nacionalismo, um regime de consenso, em maior ou menor grau dependendo do governo militar; e o controle das mídias e dos meios de comunicação (LIMA, 2009), (SOUZA, 2004).

Primordialmente, ao iniciar-se o regime militar, o presidente Humberto Castelo Branco tinha a incumbência de repensar o planejamento econômico brasileiro. Para isso, Castelo Branco lançou mão do Programa de Ação Econômica do Governo (PAEG). Acerca deste plano, seguemse os dizeres de Anita Kon (1994, p. 52):

Em 1964, foi instituído o Programa de Ação Econômica do Governo (PAEG) para o período de 1964-66, com o objetivo primordial de combater o processo inflacionário, além de acelerar o ritmo de desenvolvimento econômico do país, atenuar os desníveis econômicos setoriais e regionais, assegurar uma política de investimentos que aumentasse as oportunidades de emprego produtivo e corrigir a tendência a déficits do balanço de pagamentos.

Tomando por base o PAEG, o regime militar se estabilizou economicamente e, partindo dos ideais desenvolvimentistas em voga, realizou a proposição de inúmeros outros planejamentos socioeconômicos. Dentre estes, os mais significativos e impactantes referem-se aos Planos Nacionais de Desenvolvimento (PND), I, II e III (KON, 1994).

O primeiro PND encontra-se vigente entre 1972 e 1974, e toma por princípio a busca desenfreada pelo crescimento econômico a partir dos:

(...) investimentos em setores dinâmicos como construção e ampliação da infraestrutura do país, assim como a disseminação de uma política e ideologia de desenvolvimento nacional pautada na forte presença do Estado e de suas 
empresas públicas, estatais e sociedade de economia mista (SOUZA, 2004, p. 105).

Neste contexto, o planejamento assume um caráter instrumental e, pautando-se numa racionalidade capitalista, adquire um objetivo desenvolvimentista exclusivista e desvinculado de uma justiça social mais ampla. Desse modo, devem ser ressaltados que os tais "elefantes brancos", os inúmeros programas tecnológicos e os processos de modernização foram alheios à preocupação socioambiental (KURZ, 2001). Deste modo, não se constituindo essencialmente no desenvolvimento lato sensu. Nas palavras de Brandão (2014, p. 215):

O desenvolvimento, enquanto construção social e política de trajetórias com durabilidade, deve, permanentemente, incluir parcelas crescentes das populações marginalizadas nos frutos do progresso técnico, gerando coesão em uma escala nacional. É fundamental que esse processo transformador seja promovido, simultaneamente, em várias dimensões (produtiva, social, tecnológica etc.) e em várias escalas espaciais (local, regional, nacional, global etc.)

Entre 1975 e 1979, foi proposto o segundo PND, com fins à readequação das metas e modelos de crescimento no país, a partir de um novo contexto. Nesse período, o Brasil é afetado com a crise nos combustíveis fósseis de 1973, conhecida como "Crise do Petróleo", e deve reajustar suas ambições de crescimento a partir de um programa de substituição de importações como estratégia (KON, 1994), (SOUZA, 2004).

Já em 1979, há a necessidade da proposição do terceiro PND, como resposta a "Crise do Petróleo" deste ano; rapidamente os preços dos barris subiram mais de $37 \%$ acima do ano anterior (SOUZA, 2004). Ademais, esse planejamento urgia num momento de instabilidade socioeconômica do regime militar.

Durante a primeira metade dos anos de 1980, o regime militarista estava sofrendo grandes pressões pelos mais distintos agentes e grupos sociais. Estes questionamentos se amplificaram ainda mais com a maior organização de grupos civis, a formulação de novos partidos políticos e a volta do exílio por parte dos intelectuais (KON, 1994), (SOUZA, 2004).

Aliado a isso, a ditadura militar não justificava mais o crescimento econômico prometido, cada vez mais eram evidenciados os casos de tortura e corrupção e emergiam dissonâncias internas ao próprio regime. Esta fragilização dos governos militaristas, em associação aos novos valores democráticos que se disseminavam através da sociedade civil, fomentaram as bases valorativas que comporiam a Constituição de 1988, como bem evidencia o audiovisual "Constituinte 1987-1988", do cineasta pernambucano Cleonildo Cruz (2012), (KON, 1994), (SOUZA, 2004). 


\section{Discussões e considerações acerca dos planejamentos pós-militaristas}

Após 1985, o Brasil entra em uma nova fase de sua história, por vezes denominada de "Nova República". Como marcos desse novo período devem ser destacadas a presença do pluripartidarismo político, a instauração de um regime de dissenso, a propagação de valores democráticos e republicanos e a maior valorização e respeito as liberdades individuais. Todos esses ideais, em tese, reunidos e sintetizados na Constituinte de 1988 (SILVA, 2012) (GUIMARÃES FILHO, 1999).

Na década de 1990, esses ideais democráticos se aliaram a uma nova agenda que propunha uma ampliação no desenvolvimento do país, a agenda neoliberal. Esta compreensão sistêmica objetivava menor interferência do Estado nas questões econômicas, relegando-o apenas aos aspectos estritamente necessários (SILVA, 2012) (GUIMARÃES FILHO, 1999).

Em suma, do ponto de vista neoliberal, o papel estatal numa sociedade livre significa somente "prover os meios para modificar as regras, regular as diferenças sobre seu significado, e garantir o cumprimento das regras por aqueles que, de outra forma, não se submeteriam a elas" (FRIEDMAN, 1985, p. 32). As políticas neoliberais estavam em perfeita consonância com o cenário global do capitalismo e com as proposições enunciadas pelo "Consenso de Washington", uma das principais cartilhas dos ideais neoliberais.

Nesse contexto, algumas modificações sociais foram presenciadas, mediante aos novos valores socioculturais que emergiam. Dentre estas, vale mencionar a maior descentralização político-econômica por parte do governo federal, com os municípios garantindo maior autonomia para si. Tais processos de municipalização ocorrem consoante a maior participação e integração popular para a concepção de planos de desenvolvimento transescalares, sejam locais, regionais ou nacionais (SILVA, 2012).

No século XXI, emergem novas políticas de planejamento que almejam um desenvolvimento social mais justo e igualitário. Estas planificações, oriundas dos governos Lula, principalmente, e Dilma, objetivaram maior participação popular na elaboração das metas para a nação. Além disso, estes presidentes almejaram incessantemente, durante os seus mandatos, uma maior integração regional, com fins à redução das disparidades socioeconômicas no país (SILVA, 2012).

Como compreensão de plano governamental, Luiz Inácio Lula da Silva propôs diversos programas de integração social e valorização das diferenças. Dentre eles, podem ser citados a ampliação da política de cotas no país, o Programa Bolsa Família e o Programa Fome Zero, além 
da grande difusão de instituições públicas de ensino. Todos estes programas estavam vinculados à compreensão do fortalecimento da esfera pública enquanto algo relevante. Esta solidificação do setor público representa, nos termos de Francisco de Oliveira (1988, p. 22):

Uma negação dos automatismos do mercado e de sua perversa tendência à concentração e à exclusão. [...] o resultado surpreendente é que a esfera pública e a democracia contemporânea afirmam, de forma mais peremptória que em qualquer outra época da história, a existência dos sujeitos políticos e a prevalência de seus interesses sobre a pura lógica do mercado e do capital.

Robert Kurz (1997, p. 194), em análise do panorama socioeconômico contemporâneo, também faz o alerta em defesa da participação do Estado na vida em sociedade:

O lugar de sistemas sociais locais, pessoais, familiares e naturais de educação dos filhos, de amparo dos doentes e das pessoas necessitadas de cuidados especiais, bem como de garantia do sustento na velhice precisou ser ocupado cada vez mais por sistemas sociais nacionais, impessoais, públicos, que tinham a forma da mercadoria e do dinheiro, Não o mercado, mas tão-somente o Estado podia assumir essa tarefa, pois a economia de mercado, enquanto tal, não tem nenhuma sensibilidade e nenhum órgão para as etapas da vida humana, que caem para fora do processo incessante de transformação do trabalho em dinheiro ou que não podem, por sua própria natureza, coincidir com esse processo.

Tendo em vista as discussões e reflexões anteriormente elaboradas, percebe-se a complexidade da questão territorial no Brasil. Nos últimos decênios, os debates acerca das planificações nacionais permearam diversos governos, sob os mais diferenciados vieses ideológicos e transescalarmente, desde a esfera federal até o nível municipal. Assim, nota-se que pensar o território tem se tornado cada vez mais relevante para a compreensão dos modelos de planejamento (VITTE, 2015).

Desse modo, emergem no Brasil uma série de políticas públicas ancoradas em uma abordagem territorial, cada uma com seu enfoque específico; seus recortes espaciais e seus arranjos institucionais próprios. Diversas instâncias colegiadas (fóruns, conselhos etc.), envolvendo representantes do poder público e da sociedade civil, foram constituídas no desenho dessas políticas como instâncias de deliberação.

Dentre as novas políticas de planejamento que emergiram no século XXI, pode-se citar a Lei 10.257 (BRASIL, 2001) que inaugura o "Estatuto das Cidades". Este visa reformular a política urbana nacional, a partir da maior municipalização da gestão urbana. Desse modo, almejando um desenvolvimento mais democrático, socialmente justo, politicamente abrangente e ambientalmente sustentável para as cidades em geral. 
Vale também destacar o surgimento do Plano Diretor Municipal (PDM). Este documento conjuga-se ao "Estatuto das Cidades" e regulamenta inúmeras políticas urbanas de municípios acima de 20 mil habitantes, tais como propostas de zoneamento, áreas de especulação imobiliária, parques e zonas ambientais, regularização fundiária, dentre outras atribuições. Este plano é revisado periodicamente e conta com os mais diversos setores sociais para sua elaboração.

Portanto, percebe-se diante desta pesquisa que os processos de planificação nacional se moldam geohistoricamente a partir de dialéticas diacrônicas relativamente recentes, se comparadas as planificações das nações europeias, a datar do início do Período Republicano do Brasil. Todavia, a expressividade teórico-analítica que substanciou os planos e a difusão dos mesmos ocorreu notadamente a partir da década de 1930 (REZENDE, 2011) (PINHO, 2016).

A historiografia nacional evidencia que a disparidade ideológica entre governanças consecutivas, exceções feitas durante o Governo Vargas e o regime militar, impactou diretamente o engendramento das planificações nacionais. Logo, os planejamentos à brasileira, geralmente, ansiaram representar-se enquanto planos de governo e não de Estado, sendo brevemente executados, em diversos casos de forma incompleta, no decorrer de um determinado mandato.

Notadamente, os planejamentos governamentais nacionais alicerçaram-se, no ínterim da "Era Vargas" ao período de redemocratização brasileira, nos pilares do Nacionaldesenvolvimentismo, salvo exceções. Este modelo econômico transfigurou-se aos anseios e compreensões dos grupos políticos e/ou hegemônicos e, nos dizeres de Pinho (2016, p. 43), engendrou uma "industrialização com crescimento econômico", todavia, "resultando na concentração social da renda".

A maturação dos planejamentos nacionais continua a ocorrer, processo, strictu sensu, bastante recente, porquanto passou a considerar, efetivamente, a maior integração e popularização dos direitos sócio-políticos a partir da denominada "Nova República". No século XXI, embates entre planificações nacionalistas e internacionalistas continuam em disputa, mesmo que, por vezes, travestidas por outros termos e envoltos por novas questões e contextos, a exemplo das novas demandas transescalares e da inclusão à diversidade.

Não se pode prever como serão as planificações nacionais futuras, todavia faz-se aqui um apelo para que a maturação, manutenção e efetividade de planejamentos sejam consideradas e ressignificadas enquanto projetos de Estado. Alerta-se, por fim, consoante aos ensinamentos miltonianos, para que cada plano vindouro seja socialmente mais justo e democrático, ao não 
desconsiderar o caráter político de um mundo cada vez mais tecnificado e internacionalizado (SANTOS, 2001).

\section{Considerações Finais}

Diante do exposto acerca da gênese e do desenvolvimento do planejamento no Brasil, pode-se dizer que, em menos de um século com a real ascensão dos planos de desenvolvimento, a nação já experienciou diversos modelos de organização territorial. Deste modo, vale sempre lembrar que "tal o modo de produção, tal será o espaço geográfico" (MOREIRA, 1993, p. 35). Assim, reafirmando os múltiplos significados possíveis para o planejar espacialmente.

Como reflexão a ser feita, também vale ressaltar as numerosas posições díspares entre modelos de planejamento que se seguiram, evidenciando uma ausência de projeto de Estado claro e contínuo. Destarte, por vezes, deixando as escusas as reais intenções dos programas de planejamento.

Ademais, muitos programas se mostraram desastrosos, seja por ineficiência técnica, por inexequibilidade ou por qualquer outro impeditivo. Muitas planificações desconsideraram completamente os "custos externalizados" (LEONARD, 2011, p. 27) que os envolviam, representando um parco benefício à população em geral e um poderoso agravante aos danos sofridos pelo meio ambiente.

Por fim, adverte-se que, antes de tudo, o planejamento é uma construção social e compreendê-lo enquanto tal é basilar para a sua eficaz materialização. Sendo assim, vale enfatizar a enunciação de Gomes (1984, p. 121), tão propícia à geohistória do planejamento no Brasil: "atualmente, o espaço produtivo e o espaço social são realidades que se impõem ante qualquer projeto científico que se tenta viabilizar. Desconhecê-los significará o próprio perecimento do projeto".

\section{Referências}

ALMEIDA, R. S. O pensamento geográfico do IBGE no contexto do planejamento estatal brasileiro. In: Filosofia e história da ciência no Cone Sul: $3^{\circ}$ Encontro, Campinas. Anais... Campinas: online, 2004, p. 410-415. Disponível em: <https://edisciplinas.usp.br/pluginfile.php/5696951/mod_resource/content/1/Almeida_2004.pdf> Acesso em 31 de dezembro de 2020.

AMORA, A. S. Minidicionário Soares Amora da língua portuguesa. 19. ed. São Paulo: Saraiva, 2009.

BRANDÃO, C. A. Sobre desenvolvimento, planejamento e desafios para a pactuação multiescalar no federalismo brasileiro. In: Governos estaduais no federalismo brasileiro: capacidades e limitações governativas em debate. Organizador: Aristides Monteiro Neto. Brasília: Ipea. 326 p, p.213-232. 2014. 
BRASIL, Lei $\mathbf{N}^{\circ} 10.257$ (ESTATUTO DA CIDADE). Instituto Brasileiro de Administração Municipal. Brasília: 10 de julho de 2001.

CARNEIRO, P. A. S. Questões teóricas e tendências da Geografia Histórica. Revista GEOgraphia, Niterói, vol. 20, n. 42, p. 25-37, 2018: jan./abr. Disponível em <https://periodicos.uff.br/geographia/article/view/13830/9033> Acesso em 31 de dezembro de 2020.

CONSTITUINTE 1987-1988. Direção de Cleonildo Cruz. Produtora Independente, 2012. 1 vídeo (52 min). Disponível em <https://canalcurta.tv.br/filme/?name=constituinte_19871988> Acesso em 01 de julho de 2019.

CORRÊA, R. L. O espaço geográfico: algumas considerações. In: SANTOS, Milton (Org.). Novos Rumos da Geografia Brasileira. São Paulo: Hucitec, 1993.

FUNDAÇÃO GETÚlIO VARGAS. Plano Salte. Disponível em <http://www.fgv.br/cpdoc/acervo/dicionarios/verbete-tematico/plano-salte> Acesso em 13 de julho de 2019.

FRIEDMAN, M. O papel do governo numa sociedade livre. São Paulo: Nova Cultural (Coleção Os Economistas). p. 29-41. 1985.

GOMES, H. Geografia e planejamento. In: Boletim Paulista de Geografia. ${ }^{\circ}$ 61. São Paulo. $2^{\circ}$ semestre, $\quad$ p. $119-132.1984 . \quad 10$ Disponível em <https://www.agb.org.br/publicacoes/index.php/boletim-paulista/article/view/998/889> Acesso em 31 de dezembro de 2020.

GONÇALVES, C. W. P. Os (des)caminhos do meio ambiente. 12. ed. São Paulo: Contexto, 2005.

GUIMARÃES FILHO, R. M. A evolução do planejamento federal e a participação legislativa. Brasília: Revista de Informação Legislativa, v. 36, p. 147-185. Jul./set. 1999. Disponível em <http://www2.senado.leg.br/bdsf/bitstream/handle/id/512/r143-14.PDF?sequence=4> Acesso em: 13 de julho de 2019.

IANNI, O. Estado e planejamento econômico no Brasil. Rio de Janeiro: Civilização Brasileira, 1971.

JUSTEN, A. F.; FROTA, M. B. Planejamento e Políticas Públicas: apontamentos sobre as limitações em países em desenvolvimento. Simpósio Iberoamericano em Comércio Internacional, Desenvolvimento e Integração Regional: $8^{\circ}$ Encontro, Cerro Largo. Anais... Cerro Largo: p. 1-16. 2017.

KON, A. Quatro décadas de planejamento econômico no Brasil. Revista de Administração de Empresas, São Paulo, v.34, n. 3, p. 49-61, 1994.

KURZ, R. Os últimos combates. Petrópolis: Vozes, 1997.

“Elefante Branco". In: Folha de São Paulo, São Paulo, setembro de 2001. Disponível em:<http://www.obeco-online.org/rkurz84.htm>. Acesso em 01 de julho de 2019.

LACOSTE, Y. A geografia - isso serve, em primeiro lugar, para fazer a guerra. 19. ed. Campinas: Papirus, 2012.

LEONARD, A. A história das coisas: da natureza ao lixo, o que acontece com tudo que consumimos. Rio de Janeiro: Zahar, 2011.

LIMA, E. C. A. Ideologia e ditadura militar: a imagem do regime construída na imprensa brasileira durante o regime militar no país (1964-1985). In: Encontro Nacional de História da Mídia: $7^{\circ}$ Encontro, Fortaleza. Anais... Fortaleza: p. 1-12. 2009 
MEMORIAL DA DEMOCRACIA. Nacional-Desenvolvimentismo, a chave para o Brasil Moderno. Disponível em <http://memorialdademocracia.com.br/card/nacionaldesenvolvimentismo> Acesso em: 13 de julho de 2019.

MICHAELIS. Dicionário Brasileiro da Língua Portuguesa (Online). Planejamento. Disponível em: $<$ http://michaelis.uol.com.br/busca $\mathrm{r}=0 \& \mathrm{f}=0 \& \mathrm{t}=0 \&$ palavra $=$ planejamento $>$ Acesso em: 31 de janeiro de 2020.

MORAES, A. C. R. Geografia: pequena história crítica. 21. ed. São Paulo: Annablume, 2007.

MOREIRA, R. Repensando a geografia. In: SANTOS, M. (Org.). Novos Rumos da Geografia Brasileira. São Paulo: Hucitec, 1993.

OLIVEIRA, F. Elegia para uma re(li)gião: Sudene, Nordeste. Planejamento e conflito de classes. Rio de Janeiro: Paz e Terra, 1977.

O surgimento do antivalor - capital, força de trabalho e fundo público. In: Novos Estudos, n. 22, outubro de 1988.

PINHO, C. E. S. Planejamento governamental no Brasil: trajetória institucional, autoritarismo e democracia em perspectiva comparada (1930-2016). Rio de Janeiro: Instituto de Estudos Sociais e Políticos, Universidade do Estado do Rio de Janeiro, 2016. 440p. 2016. Tese (Doutorado em Ciência Política).

REZENDE, F. Planejamento no Brasil: auge, declínio e caminhos para a reconstrução. In: CARDOSO JR, J. C. (Org.). A reinvenção do planejamento governamental no Brasil. Brasília: $\quad$ Ipea, $2011 . \quad$ Disponível em <http://repositorio.ipea.gov.br/bitstream/11058/3182/1/A\%20reinven\%c3\%a7\%c3\%a3o\%20do\% 20planejamento\%20governamental\%20no\%20Brasil.pdf>. Acesso em: 04 de janeiro de 2021.

ROLNIK, R. O que é cidade?. São Paulo: Brasiliense, 1988.

SANTOS, M. Por uma outra globalização: do pensamento único à consciência universal. Rio de Janeiro: Record, 2001.

SARETTA, F. A política econômica brasileira 1946/1950. Revista de Sociologia e Política. Curitiba, n. 4/5, p. 113-129, 1995.

SILVA, S. P. A abordagem territorial no planejamento de políticas públicas e os desafios para uma nova relação entre estado e sociedade no brasil. Cadernos Gestão Pública e Cidadania, São Paulo, janeiro 2012.

SOUZA, A. R. As trajetórias do planejamento governamental no Brasil: meio século de experiências na administração pública. Revista UNICiências, Cuiabá, v.8, p. 99-130, 2004.

SOUZA, M. L. Quando o trunfo se revela um fardo: reexaminando os percalços de um campo disciplinar que se pretendeu uma ponte entre o conhecimento da natureza e da sociedade. Geousp - Espaço e Tempo (Online), v.22, n.2, p. 274-308, 2018.

VITTE, C. C. S. O planejamento territorial e a dimensão espacial do desenvolvimento: algumas das experiências recentes no Brasil. Revista Política e Planejamento Regional, Rio de Janeiro, maio 2015.

Recebido em 25/09/2020 - Aprovado em 27/01/2021 